\title{
The Role of State Leadership in the Incidence of International Governance
}

\section{Barbara Koremenos}

University of Michigan

\section{Abstract}

To understand leadership in international governance, I begin at the structural level with state actors. A simple framework that relies on state interests and material power can shed light on why powerful states take on leadership roles in some negotiations (e.g. arms control) but not in others (e.g. human rights). States attempting to cooperate to realize joint interests or solve problems often face a set of common and persistent obstacles. These obstacles, which I call 'cooperation problems', can make otherwise beneficial cooperation difficult to achieve. I argue that the particular combination of underlying cooperation problems present in an issue affects a powerful state's desire to take on a leadership position with respect to the incidence of international cooperation - that is, agenda setting by putting forth the first draft of an international agreement addressing the issue and remaining in control of subsequent drafts. Because, from a policy point of view, the most interesting cases are those that involve distribution problems, I focus on the following two combinations of problems: distribution with coordination and distribution without coordination. I use the examples of the Nuclear Nonproliferation Treaty, the Antarctic Treaty, the Convention on the Elimination of Racial Discrimination and the Convention Against Torture to illustrate the theoretical discussion.

In this article, I explore the role of leadership in the incidence of international governance structures. I focus on individual international agreements as one important form of international governance. Leadership is conceptualized as state leadership. As highlighted in the introductory article, the exercise of leadership pertains to the ability of a state or group of states to bring together actors characterized by different interests to achieve a common goal. In particular, I focus on agenda setting as leadership - that is, which state or group of states take on a leadership position in initiating cooperative endeavors by putting forth the first drafts of an international agreement and, for the most part, remaining in control of subsequent drafts. ${ }^{1}$

I assume that negotiations are about designing treaties that help states realize their interests rather than about persuading states to change or define their interests. Therefore, depending on the underlying strategic structure, taking a leadership position in the initial negotiations may be important to states. Specifically, I argue that powerful states often want institutionalization through international agreements (international law) and want to control its terms through agenda setting in the presence of certain combinations of problems but not others.

Therefore, I consider state power in the material sense. As I will elaborate, material power can be very useful (but is not always necessary) in exerting leadership, enabling an actor to supply positive and/or negative incentives to other actors to encourage them to buy into the leader's agenda. Put bluntly, not only is the goal often achieved; the goal is one that is aligned particularly closely with the state leader(s)' preferences - i.e. the agreement text reflects closely the interests of the powerful. Even in this case, governance outcomes are still altered by the exercise of leadership because, in its absence, the international agreement would not be achieved.

My basic theoretical premise is that the cooperation problem(s) underlying the cooperative endeavor (or put differently, the underlying strategic structure that reflects the joint and conflicting interests of state parties) are key to understanding the necessity of leadership in the initiation of international governance. Cooperation problems also affect the nature of that leadership; do powerful states take control of the agenda or do they allow others to take on that leadership role?

What do I mean by cooperation problems? States attempting to cooperate to realize joint interests or solve problems often face a set of common and persistent obstacles regardless of the substantive issue over which they are cooperating. These obstacles, which I call 'cooperation problems', can make otherwise beneficial cooperation difficult to achieve. For example some issues, such as trying to ban chemical weapons or trying to promote the rights of women, pose huge information obstacles: how can one state know what other states are doing? Such uncertainty about behavior is 
absent in issue areas like the settlement of a bilateral debt, for which behavior is quite transparent. Fears that one's partner in cooperation might cheat on an agreement might make certain states unwilling to go forward with cooperation, despite the gains that could potentially be realized. Likewise, uncertainty about whether cooperation will be beneficial in all possible future conditions might make states forego current cooperation and the short-term gains it could bring simply because cooperation is perceived to be too risky.

The focus on cooperation problems follows the Continent of International Law (COIL) research program (Koremenos, 2013, 2015), which argues that the procedural or design dimensions of international agreements can be used to solve such problems, thereby increasing the incidence and robustness of international governance. Here I use this same framework to explore the need for and nature of leadership in institutionalizing international cooperation through some kind of governance structure like an international agreement. COIL identifies eight distinct cooperation problems that states potentially face, alone or in combinations. However, given that this is the first application of the COIL framework to issues of leadership, I begin with two cooperation problems - distribution and coordination (defined in the next section) - and discuss what their interaction implies for the necessity of state leadership in bringing about international governance.

In the following section I introduce the underlying assumptions of the COIL framework as well as my assumptions about what happens to state interests during an international negotiation. I elaborate the four possible combinations of distribution and coordination problems, briefly bringing them to life for the reader. I discuss which combinations might demand leadership for their solution and whether powerful states are likely to fill the agenda-setting role. I apply the framework by examining the initiation of four international cooperative endeavors: the Nuclear Nonproliferation Treaty, the Antarctic Treaty, the Convention Against Torture and the Convention for the Elimination of Racial Discrimination. I conclude with policy implications and ideas for future research.

\section{Assumptions}

First, states are the main actors in global governance or international cooperation. That is not to say that other actors, like NGOs, are not influential. Nonetheless, such actors are not the major force behind global order. At the core of global cooperative activity are states exercising their power and realizing their interests through international agreements and institutions - that is, the body of international law. ${ }^{2}$
Second, states are rational actors that pursue their selfinterest when facing cooperation problems. Following the tenets of rational choice theory, no assumption is made about the sources of state preferences. States can care about increasing their wealth, making themselves more secure, protecting the environment and seeing their human rights standards embraced by others. This broad set of goals is not inconsistent. Nor do we find states acting 'less rationally' in some issue areas or 'more rationally' in others. ${ }^{3}$

Regarding the implicit 'states as unitary actors' assumption employed here, I assume there exists some aggregation mechanism at the domestic level that yields a state preference at the international level. Thinking about states as unitary actors is without doubt a fruitful theoretical assumption, but not one that necessarily yields a complete empirical picture. Still, the assumption serves as a useful baseline for later refinements.

With respect to what happens during the negotiation, I assume that the leader or agenda setter puts forth the first draft of the agreement and remains in control of subsequent drafts. I differ in this regard from Hawkins (2004), who states that 'the drafting process provides a setting in which persuasion can take place' (p. 784). In other words, I assume that state interests are rather defined when the drafting process begins. Negotiation may provide an opportunity for learning more about the issue area or about one's partners' preferences regarding cooperation, but rarely do interests change during the process; this is in contrast to Hawkins (2004), who argues that 'state interests are sometimes uncertain and can be formed over time through processes of communication and persuasion' (p. 780).

These simplifying assumptions may seem to place this analysis at one extreme of the rich literature on leadership and international politics. ${ }^{4}$ As Robert Jervis states smartly in a recent article, scholarship on leadership in international politics is 'commonly linked to the level-ofanalysis question' (Jervis, 2013, p. 153). Jervis looks at the individual level but adopts a relatively moderate stance regarding the degree to which individual leaders exhibit agency with regard to foreign policy. In fact, some of his conclusions are quite consistent with the more 'extreme' assumptions made here. For example, Jervis claims that because political leadership may be restricted to a homogenous body of candidates, political office tends to socialize its office holders and leaders experience constraints on their power, individual political leadership may have little effect on the interests and international cooperative behavior of the state (Jervis, 2013).

Because international cooperation problems as contemplated by the COIL framework are consistent, they are necessarily integrated into a state's foreign policy. Jervis's assessment of power in the American presidency reflects this observation: the persistent needs and 
characteristics of a state will shape the leaders themselves as well as the policies that they support. The common ground and potential complementarities among the various approaches to leadership are worthy of future research.

\section{Cooperation problems}

At the core of international politics are problems of enforcement, distribution and commitment as well as struggles for power and influence, all of which are exacerbated by multiple kinds of shocks, uncertainties and distrust. Even the most optimistic among us would have to admit that international political interactions are characterized by some subset of these problems at least some of the time.

In this section, I identify two distinct and recurrent cooperation problems that states may face either in isolation or together when they attempt to realize the gains of cooperation.

Let me begin with distribution problems. A distribution problem captures the different preferences states have over which alternative cooperative agreement to implement.

At one extreme in which actors prefer the same cooperative outcome, there is no distribution problem. Distribution problems are greater in settings like arms control, when actors want to cooperate but prefer alternative cooperative outcomes regarding which weapons to ban. At the other extreme, in a zero-sum game like setting quotas for oil or coffee exports, the problem is strictly distributive because a better outcome for one leaves less for the others.

No major issue area is exempt from distribution problems - not even human rights. Just as issues like the death penalty, abortion and torture ignite major debates among parties domestically, these same issues animate human rights negotiations - the majority of which are as fraught with distribution problems over which rights to include, which to prohibit and even how to define the rights themselves. Similarly, trade, disarmament and environmental negotiations include debates over import duties, which weapons to ban or reduce and allotted quotas for sub-issues like fishing, respectively.

Consider the challenges in the mid-1990s when designing a cooperative agreement to solve the problems of North Korea's nuclear proliferation. At the time the USA, South Korea and Japan essentially had to pay a bribe to North Korea in exchange for North Korea remaining a part of the Nuclear Nonproliferation Treaty (NPT) and allowing International Atomic Energy Agency (IAEA) inspections. The bribe is both very costly and controversial. As Ambassador Stephen Bosworth stated: they are three countries dealing with a question in which they have a common stake, but over which they have severe differences on how to deal with the Democratic People's Republic of Korea (quoted in Wit, 1999, p. 64). Thus the various ways to change the incentives of North Korea and the various ways of splitting the costs of doing so are at the heart of the distribution problem.

While all agreements require 'coordination' on agreement text, COIL has a very specific definition of a coordination problem. In situations characterized by underlying coordination problems, actors must coordinate on exactly one outcome to be better off cooperating. The worse it is to 'miss' some specific solution, the more severe the coordination problem.

The New START treaty between the USA and Russia, and superpower arms control treaties more generally, are characterized by an underlying coordination problem. Suppose a superpower arms control agreement simply stipulated 'reduce ballistic weapons'. Then reducing by any amount would constitute compliant behavior. But if the two sides reduce weapons to different degrees in such a competitive and sensitive issue area, it could be argued (and has been by many US senators) that at least one side is hurt very badly. Importantly, that state that reduced more would prefer not to have had any agreement at all.

It is important to note that traditional $2 \times 2$ game representations sometimes conflate distinct cooperation problems like distribution and coordination. Consider the famous 'battle of the sexes' game: two actors share the desire to pursue a common goal but have different preferences with respect to cooperative outcomes. A couple attempting to plan a date night, for example, might agree on going out but disagree on where they should go. Cooperative endeavors characterized by a battle-ofthe-sexes-style dilemma feature challenges with respect to both distribution and coordination: 'while both players want to go out together, the conflict [distribution] element is present because their preferred activities differ, and the coordination element is present because they may end up going to different events if communication between them is limited' (Lau and Mui, 2008, p. 154). Put differently, coordinating on an exact movie (or ballet) is not mentioned as a necessary condition of one of the Pareto optimal outcomes of the battle of the sexes. Yet most would agree that, in such a situation, coordinating on different movies is worse than no coordination at all!

In the following sections, I elaborate the four possible combinations of distribution and coordination problems. (Much of this draws on Koremenos and Hong, 2013 and Koremenos, 2015.) Various combinations of distribution and coordination are then used to explain the importance of leadership as well as the role power plays (or does not play) in the initiation of four international cooperative endeavors: the Nuclear Nonproliferation Treaty, the Antarctic Treaty, the Convention Against Torture and the Convention for the Elimination of Racial Discrimination. 


\section{Both distribution and coordination}

In many issue areas where there is a distribution problem, there is also a coordination problem in which complete coordination is necessary (e.g. one clear boundary, one clear technical standard). Take the example of export quotas in a commodity agreement. When states wanted to cooperate to stabilize and raise the price of coffee, they needed to coordinate exactly on a supply of coffee to ensure that the price would be what it was intended to be. Oversupply by one state would cause the price to change, and defections in such strategic situations can cause the entire agreement to fail. This was the case for many attempts at coffee cooperation before the 1962 International Coffee Agreement (Bates, 1997; Koremenos, 2002). Not only is complete coordination necessary or the parties will be worse off, but states also have to divide the coffee market - the epitome of a distribution problem.

\section{Distribution without coordination}

By contrast, consider a human rights agreement (HRA) that calls for the abolition of child labor. If some states define a child as someone under 18 and act accordingly while others define a child as someone under 15 , as long as both are reducing child labor however they define it both states are better off with the agreement than without it. Surely the state that defines a child as under 18 would prefer the other state to act in a similar fashion, but it still prefers the other state reducing child labor for those under 15 than not reducing it at all.

\section{Only coordination}

In the security issue area, bilateral efforts aimed at protecting classified information are extremely important among allies. Before cooperation can commence, states must first coordinate on what is considered classified and who exactly has access to such information. The underlying problem is not really about who gets how much.

\section{Neither coordination nor distribution}

Some cooperative endeavors have neither coordination nor distribution problems underlying them, like those that encourage sharing of scientific information. For example, there is a set of agreements by which Germany sends scientists to developing countries to help them with issues like plant protection.

\section{When is leadership necessary and will the powerful states lead?}

In this section, I consider the four possible combinations of distribution and coordination problems. I begin with distribution without coordination because the spatial model introduced can then be used to explain the other three combinations. In the subsequent section, I present the case studies.

\section{Distribution without coordination: nonpowerful state(s) can take leadership}

As briefly mentioned earlier, HRAs are often the subject of an underlying distribution problem: each state wants to see its preferred norm be the one that is codified or exported to other states. But if State B embodies a slightly different norm than the one promulgated by State A, State A can keep its norm and is not worse off than it would be without an agreement. I now elaborate what this combination of 'distribution but no coordination' looks like in a typical HRA negotiation and the implications for who takes on the leadership position.

Consider the negotiation of a HRA as a strategic interaction between two states, State 1 and State 2. These two states have asymmetric preferences over a particular substantive human rights norm yet they believe in the importance of human rights standards. This common interest sets them apart from certain other states that have no interest in setting and spreading human rights standards.

Suppose the standard in question is women's rights and the scale of this norm ranges from 1 to 10 . The norm equals 1 when women are considered not equal to men in any way and 10 when women are not only considered equal in every way but also all national laws and pay rates must be changed to reflect this standard. State 1 (a middle-power state) has norm 8, including nondiscrimination against women in the workplace enforced by a state agency, while State 2 (a very powerful state) has norm 6, including nondiscrimination against women in the workplace. Consider the following scenario. If either state needs to change its standard, it prefers no agreement at all to an agreement with a higher or lower standard. Still, although both states strongly prefer to remain with their own specific norms, as long as they are not pressured to switch to the other's standard and thereby pay the implementation costs of such a change, they accept that the other party will remain regulated by its own norm. They prefer an improved international human rights standard on women's rights to no agreement at all.

The outcome just described can be achieved through the design provision of vague language, a form of flexibility (Koremenos and Hong, 2013; Koremenos, 2015). The language of the treaty could read, 'women will not be discriminated against in the workplace, and this right shall be enforced by state agencies when possible given constitutional or other constraints', or 'nondiscrimination in the workplace enforced by state agencies, as long as the new policies do not run counter to national laws'. Employing 
such language, HRAs accommodate states with asymmetric preferences over the specifics of substantive human rights standards but with a common desire to raise standards for third parties. Importantly to States 1 and 2 (represented by Group A in Figure 1), states whose behavior reflects norms that fall below what can be interpreted through the vague language (states in Group B) are forced to change at least somewhat if they want to be in compliance with the agreement.

What does the spatial diagram imply for leadership? Leadership is needed to set the agenda by writing a draft agreement that reflects Group A's general norms; Group A can then attempt to export these norms to others, like Group B. However, because of the lack of a coordination problem, leadership can be taken by any state in Group A. Thus State 1 in this example can set the agenda; the more powerful state (State 2) accepts State 1 's leadership as long as the agreement terms are vague enough to accommodate State 2's norms. In other words, by allowing State 1 to write the first draft and set the agenda, State 2 is not being persuaded to change its interests; rather, State 2 can make minor (if any) changes in its policy if flexibility in language is employed. Likewise, State 2 can add reservations to the agreement if it is an outlier on any particular provision. Thus, in situations of distribution without coordination, nonpowerful state(s) can take leadership and write the draft agreement.

\section{Both distribution and coordination: powerful states take leadership position}

Now consider once again Figure 1 but with the following change: this time states will be better off cooperating only if one point along the horizontal policy space is chosen. That is what a distribution and coordination situation would resemble. It is very much in the spirit of Krasner's (1991) 'Global Communications and National Power: Life on the Pareto Frontier'. A major contribution of Krasner's article was the recognition that, unlike the simple $2 \times 2$ game, in the typical cooperative endeavor states possess a wide range of choices (i.e. many possible cooperative outcomes), often with different distributional consequences. If actors prefer different outcomes, this range of possibilities creates bargaining problems. Therefore, a powerful state is likely to be interested in seeing its most preferred outcome along this Pareto frontier chosen. $^{5}$

Thus not only must the states solve the distribution problem, they must also coordinate on exactly one way of solving it. The terms cannot be left vague to solve the distribution problem; the coordination problem implies that one solution must be chosen otherwise the whole point of the agreement falls apart. This is easy to imagine if one were to think of the horizontal line as different ways to divide a body of water that is likely to have valuable mineral deposits or fish. States need one boundary, just as they do with respect to other territorial issues. Leadership is needed to set the agenda - to propose a way of choosing the outcome. Powerful states will want to harness their resources to make sure the cooperative agreement reflects their desired policy.

\section{Coordination without distribution: no leadership necessary or leadership by expert, not powerful}

This is what Krasner (1991) refers to as a simple coordination game where no prior investments have been made and every possible point is preferred equally. Put differently, the parties' payoffs are symmetric across the outcomes. Leadership is not always necessary; a randomization device could simply choose a point. Alternatively, an expert might be useful in dictating the terms of the agreement. By this I mean states with material power are unlikely to exert any effort to control the agenda given that there are no distributional consequences. If states are indifferent among outcomes in that regard, allowing an expert to choose or simply randomizing among the outcomes in order to choose one is preferable.

As an example, one of the agreements in Koremenos's COIL random sample is the 1964 'Agreement Concerning the Collection of Bills, Drafts, etc'. The agreement establishes a system for transferring funds internationally, and states agree to institute a system for exchange of bills and other collection mechanisms in their countries. The distribution consequences are minimal but the coordination demands are acute. ${ }^{6}$

\section{Neither coordination nor distribution: no leadership necessary}

Some cooperative endeavors have neither coordination nor distribution problems underlying them, like those that encourage sharing of scientific information. For example, there is a set of international agreements by which Germany sends scientists to developing countries to help them with issues like plant protection. These are typically bilateral agreements under which one state gives aid or other assistance to another. Figure 2 summarizes each of the possible combinations and the implications for leadership and power.

\section{Cases}

In this section, I will use the examples of the Nuclear Nonproliferation Treaty (NPT), the Antarctic Treaty (AT) and the Convention on the Elimination of Racial Discrimination (CERD), with an extremely brief discussion of the 
Figure 1. Vague language to solve distribution but no coordination.

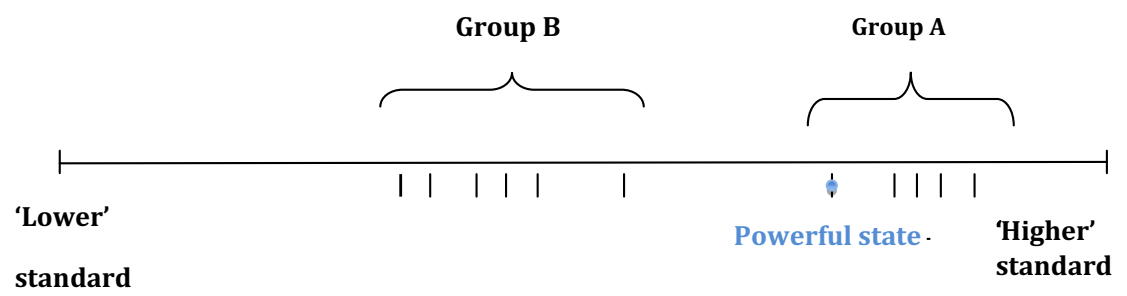

Convention Against Torture (CAT), to illustrate the theoretical discussion. Because, from a policy point of view, the most interesting cases are those that involve distribution problems, ${ }^{7}$ I focus on the following two combinations of problems: distribution with coordination and distribution without coordination. Specifically, I examine how the particular combination present in an issue area affects a powerful state's desire to take on a leadership position with respect to the incidence of international cooperation - that is, agenda setting and putting forth the first draft, and remaining in control of subsequent drafts.

\section{Both distribution and coordination: powerful states take leadership position}

With respect to the NPT, the two superpowers (the USA and USSR) faced a distribution and coordination problem. Arms control in general is often characterized by these two problems in combination. 'Who gets what and how much' is at the heart of the distribution problem. Moreover, the balance of power would be affected greatly by whether NATO and/or the Warsaw Pact states were able to have nuclear weapons on their territory. Leaving such things up to the discretion of the actors would be too risky and would have undermined the entire endeavor. In other words, unless the USA and USSR were quite clear about the identity of the have and the have-nots and that the resulting coordination point would preserve the existing balance of power, neither would have agreed to the NPT.

The NPT's most substantive articles are a product of preliminary negotiations between the USA and the USSR on key issues and minimum demands. In other words, the two superpowers took over leadership and set the agenda even though the treaty was largely negotiated in the context of an Eighteen-Nation Committee on Disarmament. One mechanism through which the superpowers were able to control the committee was its cochair system, which facilitated compromise by prioritizing discussion pertaining to their own agendas (Bourantonis, 1997). In fact, in the treaty itself the articles and clauses that impose restrictions on nonnuclear weapon states (NNWS) use precise language and create a practical framework for enforcement by the IAEA. Soviet and
American influence resulted in relatively tighter restrictions than may have otherwise been imposed. For example, the Treaty for the Prohibition of Nuclear Weapons in Latin America, a product of nonnuclear developing states, allows its members to carry out explosions for peaceful purposes whereas this is prohibited by the NPT (Goldschmidt, 1980). In exchange for these restrictions, NNWS sought an expansion of the treaty scope to their benefit. Their interests are reflected in: Article IV, which reaffirms the right of all members to pursue peaceful nuclear technology; Article $\mathrm{V}$, which encourages the transfer and proliferation of peaceful nuclear technology from nuclear weapon states to NNWS; and Article VI, which promotes nuclear disarmament. However, the language of these articles is extremely vague and nonbinding. Article IV simply reaffirms an existing right. Article V demands 'appropriate measures' to be taken for the sharing of 'potential benefits' of peaceful nuclear technologies, essentially allowing nuclear weapon states to decide arbitrarily what and how much (if any) technology is to be shared. Article VI merely calls for disarmament talks in 'good faith' at a nonspecific 'early date'.

That the negotiations largely sidelined the concerns of NNWS is evidenced by the 1965 UN General Assembly resolution 2018 calling for a 'proper balance of mutual obligations and responsibilities' in negotiations over nuclear nonproliferation. However, 'the nonaligned, NNWS were not a solid bloc with a single point of view, but rather were divided among themselves and constituted a whole spectrum of opinion' (Epstein, 1980, p. 122), which undermined their ability to negotiate as a bloc. The more militant ones, such as Chile, India, Brazil and Pakistan, linked the concession of giving up the right to possess nuclear weapons with the necessity for disarmament on the part of the existing nuclear weapon states. Moderates such as Mexico and Sweden wanted the NPT to be a step forward towards an eventual disarmament treaty, but regarded disarmament as too important to be used as a bargaining chip in this one (Bourantonis, 1997, p. 352). Both groups agreed that they were being ignored by the superpowers and eventually coalesced their demands into broad security guarantees, nuclear disarmament and the proliferation of nuclear technology. In 1966, the General Assembly resolved to 
Figure 2. Combinations of cooperation problems and implications.

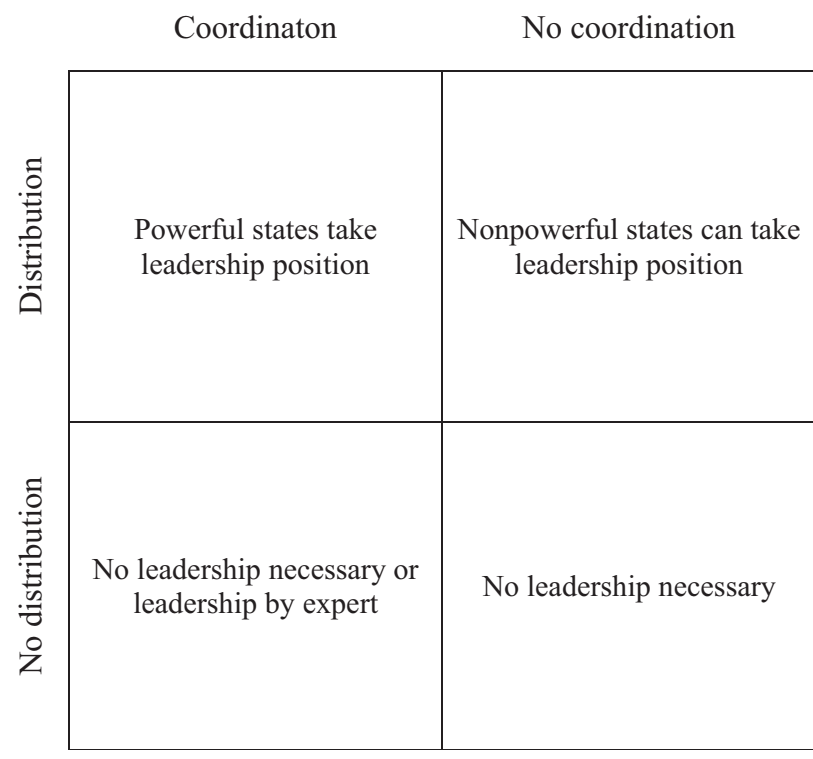

call for an exclusively nonnuclear state conference to decide on how to best pursue these objectives (General Assembly, Resolution 2153).

In response to this, the USA and the USSR used their allies in the General Assembly to pass Resolution 2346 in December 1967, which states that 'it is imperative to make further efforts to conclude such a treaty at the earliest possible date' and 'asked the committee to submit a draft treaty before 15 March 1968' (Bourantonis, 1997, p. 354). The calls for the relatively swift conclusion of the NPT limited the potential expansions of scope in areas such as disarmament and peaceful technology sharing.

The result of the clash between the demands of the nonaligned/nonnuclear movement and the General Assembly's time constraints were Articles IV, V and VI. These articles clearly respond to the general will of the NNWS to receive 'compensation' for their renouncement of nuclear weapons. However, the articles are vague and only guarantee a right to pursue peaceful applications of nuclear technology, without binding the nuclear powers to disarm or provide peaceful technological assistance.

In sum, the superpowers submitted identical drafts to the Eighteen-Nation Committee on Disarmament with terms that reflected their interests but also with the knowledge that they needed to appease the NNWS. The extremely asymmetric treaty terms by which the permanent UN Security Council members keep their weapons and all other states forsake them cannot be seen as anything other than reflective of the preferences of the powerful states. In the case of the NPT, the two superpowers took leadership in drafting the treaty, dictating its terms and keeping control of its subsequent drafts, tweaking it only to the extent necessary to get enough of the NNWS on board. The limited duration, five-year review conferences, vague arms control provision and technology exchanges are the 'compromises' made by the two states holding the power in the issue area. (Similarly, Heritier and Prakash (2015) argue that the EU made the necessary concessions to the chemical industry when it took leadership in chemical regulation.)

The AT is also best described with this underlying strategic structure given the complicated and contested territorial issues and the potential mineral resources on the continent. The nature of the distribution and coordination problem combination stems from the fact that, in the 1950s, seven states claimed sovereignty over Antarctica. The USA wanted neither to recognize the territorial claims of these states nor to renounce the potential to make future claims. The USA was also concerned about Soviet interest in Antarctica given that the USSR formed an institution to conduct Arctic research in the 1920s and expanded it to included Antarctica in the 1950s. Given the potential value of the continent, the USA wanted to maintain control over both scientific research and mineral extraction. Allowing claims to Antarctica to be recognized in international law was against the USA's interests. The potential division of valuable territory is characterized by both distribution and coordination problems.

After participating in a successful International Geophysical Year (IGY) (1957-58), the USA took leadership on this issue by deciding a treaty was in its interests and hence moved quickly. The USA invited the 11 other active IGY states (Argentina, Australia, Belgium, Chile, France, Japan, New Zealand, Norway, South Africa, the USSR and the UK) to a closed conference in Washington, DC that resulted in the AT. The USA demanded an early date for the start of the negotiating conference and wrote the original and final drafts of the treaty.

Reflecting USA interests (US National Security Council, 1958), the treaty stipulates that Antarctica should forever be used for peaceful purposes exclusively, prohibits any kind of military measures, prohibits nuclear explosions and disposal of radioactive waste, guarantees freedom of scientific research and promotes scientific exchange of both personnel and results, and establishes a comprehensive system of on-site inspection to ensure the observance of the treaty. Significantly, Article IV removes the potential for sovereignty disputes by stipulating that the legal position with respect to the sovereignty of treaty parties is not prejudiced by any acts or activities taking place during the lifetime of the treaty and that no new claim, or enlargement of an existing claim, may be asserted while the treaty is in force (US Department of State, 1959). Moreover, the position of the USA and the (then) USSR is protected by a paragraph stating that nothing in the treaty shall be interpreted as 'a renuncia- 
tion or diminution by any Contracting Party of any basis of claim to territorial sovereignty'. In other words, according to Article IV, the parties agree not to press or surrender their divergent views regarding territorial sovereignty. This was the solution to the distribution problem and coordination problem desired by the US. Consistent with Krasner (1991), the powerful state chose the equilibrium outcome.

\section{Distribution without coordination: nonpowerful states can take leadership}

The UN Sub-Commission on Prevention of Discrimination and Protection of Minorities to the Commission on Human Rights controlled the agenda for the negotiation of the International Convention on the Elimination of All Forms of Racial Discrimination (CERD). The member states composing that Sub-Commission in 1964 (the time CERD was drafted) were the USA, the United Arab Republic, France, the UK, Italy, Mexico, The Philippines, the USSR, Poland, India, Austria, Sudan, Finland and Chile (UN Economic and Social Council [ECOSOC], 1964b). Thus the group was composed of both powerful states and nonpowerful states. There is no evidence that the powerful states used their material power to promise or threaten other states with rewards or punishments to take control of the agenda. Rather, both the USA and USSR, for instance, proposed amendments to certain controversial text around which there was a distribution problem, but in the end did not win out.

The drafting of Article 4, which engages freedom of speech, provides a particularly good example of what happened during the negotiations when distribution problems were present within the Sub-Commission. Article 4 states:

Parties condemn all propaganda and all organizations which are based on ideas or theories of superiority of one race or group of persons of one colour or ethnic origin, or which attempt to justify or promote racial hatred and discrimination in any form, and undertake to adopt immediate and positive measures designed to eradicate all incitement to, or acts of, such discrimination (UN General Assembly, 1965).

The USA submitted a draft of Article 4 that did not have the same bearing on freedom of speech as the final text. This draft seems to have been overshadowed by more 'radical' drafts and amendments put forth in different sessions and in different bodies (including the Commission on Human Rights) by The Philippines and Mexico in the Sub-Commission and the USSR and Poland in the Commission on Human Rights. Representatives from The Philippines and Mexico wrote the initial text that was eventually adopted by the Sub-Commission and that most resembles the final draft eventually adopted in 1965 .

During the Sub-Commission's 20th session, the main point of contention regarding Article 4 was its intent to 'declare illegal and prohibit organizations, and all organized propaganda activities, which promote and incite racial discrimination' (UN ECOSOC, 1964a, p. 38). The USA proposed an amendment to the article that would require the insertion of the words 'activities of' before 'organizations' (UN ECOSOC, 1964a, p. 39), most probably in the effort to protect the right of these organizations to exist and the right of the people to consider themselves members.

Several representatives also felt that the purpose of the paragraph was to penalize activities or acts prohibited by law and not ideas, thoughts or intentions that did not lead to acts. They pointed out that any attempt to outlaw potentially harmful speech, publication and association in the absence of any act would pave the way to grave abuses by authorities in deciding whether a particular expressed opinion was punishable or not (UN ECOSOC, 1964a).

The American amendment was then withdrawn in favor of a Costa Rican amendment to the same effect. In an effort to reconcile both perspectives, the Costa Rican amendment suggested the article include the words 'or the activities of organizations, as appropriate' after the word 'organizations' (UN ECOSOC, 1964a, p. 39). The USSR took a polar opposite position, advocating for the replacement of the word 'or' in the Costa Rican amendment with the word 'and' (UN ECOSOC, 1964a, p. 39). Ultimately, the Sub-Commission accepted the CostaRican-revised amendment ('or the activities of organizations, as appropriate'). Somewhere along the way, however (presumably in the General Assembly), the amendment was removed.

In the end, the USA, UK, and France lodged reservations against Article 4 for its alleged infringement on the rights to freedom of speech, freedom of expression and freedom of association, 'recognized as basic human rights in articles 19 and 20 of the Universal Declaration of Human Rights' (UN ECOSOC, 1964a, p. 41). They were certainly not persuaded to redefine their interests with respect to free speech. Nor did they exercise power to control the wording of the article to reflect their interests. The absence of a coordination problem did not necessitate this strategy.

This example makes the point that states come to HRA negotiations, as they do other negotiations, with clear interests and are not persuaded to change or define or redefine their interests during the negotiation. Rather, the particular combination of cooperation problems underlying many HRAs allows flexibility to be used so states can interpret and/or tailor the treaty to fit their preferences.

My argument is consistent with Hawkins' (2004) description of the CAT negotiations: Sweden seems to 
have acted as the agenda setter of the CAT negotiation as it provided the first draft. Hawkins also states: 'Sweden, and later the Netherlands, provided most of the initiative to keep the negotiations moving forward, and the US did not make the treaty a priority' (Hawkins, 2004, p. 797).

Thus given the absence of a coordination problem, leaders of human rights negotiations are often less powerful states who have an interest in promoting human rights standards, i.e. the set of Scandinavian states. NGOs and experts sometimes partner up with such states and influence the drafting of the HRA texts. Reservations and imprecision allow powerful states to be content with treaty terms over which they did not exhibit leadership, as this quote from US Secretary of State George P. Shultz makes clear:

In view of the large number of States concerned, it was not possible to negotiate a treaty that was acceptable to the US in all respects. Accordingly, certain reservations, understandings, and declarations have been drafted to reflect the federal system of the US, to clarify the definition of 'torture,' to ensure that the provisions relating to extradition and deportation are consistent with US treaty obligations and US law, and to reserve both to the compulsory jurisdiction of the International Court of Justice and to the competence of the Committee against Torture to initiate investigations of the US (Shultz, 1988, pp. v-vi).

\section{Conclusions}

A simple framework that relies on interests and power can shed light on why powerful states take on leadership roles in some negotiations (e.g. arms control) but not in others (e.g. HRAs). A few policy implications can be highlighted:

1. Powerful states do not take unconditional leadership roles in setting the agenda for the negotiation of international agreements. They do so only when their interests cannot be served without leadership, as in when distribution problems are combined with coordination problems.

2. Persuasion is unlikely to occur during human rights negotiations; rather, HRAs are strategically or rationally designed to be vague and tend to have reservations so that varying (yet stable) interests can be accommodated. This does not imply that powerful states are not interested in human rights cooperation, since they are careful about the reservations they add.

3. Middle-power states can take on true leadership under certain conditions, even when powerful states are a part of the multilateral cooperative endeavor.
This article also suggests a future avenue of research. While international cooperation starts with negotiation, the implementation stage of any cooperative endeavor is also important. Future work can explore whether particular cooperation problems can explain whether powerful states take on a leadership role in the implementation of a treaty. For example, in those endeavors characterized by an underlying enforcement problem - that is, incentives to defect and free ride on another's cooperation powerful states may be more likely to take a leadership position in implementation; their payoffs are adversely affected by others' defection. When enforcement problems are absent, powerful states are less interested in taking leadership with respect to implementation - as in many HRAs.

Moreover, Mattli and Seddon (2015) suggest that when powerful states have an interest in implementation but lack the ability to identify noncompliance, they may encourage NGO monitoring even when the formal monopoly on monitoring lies with the member states or an intergovernmental organization (IGO) composed of these states. These NGOs would be rule supporters, not rule makers. As Mattli and Seddon (2015) state: 'cooptation arrangements also vary according to the number of available partners. IGOs coopting easily substitutable rule-supporters pay the lowest price when enlisting external resources' (p. 24). Given the number of NGOs available for monitoring, powerful states are thus likely to retain leadership in implementation if their interests so mandate. ${ }^{8}$

\section{Notes}

I thank Raya Saksouk, Julia Gysel, Aseem Prakash, Adrienne Heritier, Nicholas Hazen, David Garavito and Gianluca De Gasperi Delpino for helpful comments or research assistance. I also thank the participants of the conference on 'Global Governance and the Neglected Issue of Leadership', held at the European University Institute on 13-14 December 2013.

1. See Schoeller (2015) for a complementary analysis of how Germany set the agenda with regard to Europe's Fiscal Compact.

2. See Koremenos et al. (2001), which defines 'international institutions as explicit arrangements, negotiated among international actors, that prescribe, proscribe, and/or authorize behavior' ( $p$. 762). Thus each piece of international treaty law is considered an international institution. I use the terms international law, international agreement and international institution interchangeably henceforth.

3. See Koremenos (2015) for large-scale confirmation of the fact that states tend to design agreements in ways that solve cooperation problems regardless of the issue area using a random sample of international agreements across the issue areas of economics, environment, human rights and security.

4. See, for example, Hermann (1980) and Saunders (2011) for analyses that zero in on the individual as an important explanatory factor of foreign policy. 
5. This is similar to Schoeller's (2015) argument about the supply of leadership.

6. In the COIL sample, each particular agreement is characterized by the presence (coded as high or 1) or absence (coded as low or 0 ) of eachz possible cooperation problem. In reality, all situations are characterized by almost all cooperation problems to some degree, but COIL codes them as existing if they are present in high as opposed to low levels. For example, uncertainty about preferences or type always exists to some degree in any interaction, but a situation has to be characterized by high uncertainty about preferences (e.g. the USSR and USA during the Cold War as opposed to the USA and Canada during the same period) for it to be considered present.

7. See too, Heritier and Prakash (2015).

8. Similarly, Saz-Carranza (2015) argues that the individual in charge of a large IGO leader need not have a conflicting relationship with his/her principal. The extent to which the underlying cooperation problems that necessitated the creation of the IGO drive this principal-agent relationship is worthy of future research.

\section{References}

Bates, R. (1997) Open-economy Politics: the Political Economy of the World Coffee Trade. Princeton, NJ: Princeton University Press.

Bourantonis, D. (1997) 'The Negotiation of the Non-proliferation Treaty, 1965-1968: a Note', The International History Review, 19(2), pp. 347-357. doi:10.1080/07075332.1997.9640788.

Epstein, W. (1976) The Last Chance: Nuclear Proliferation and Arms Control. New York: Free Press.

Goldschmidt, B. (1980) 'The Negotiation of the Non-proliferation Treaty (NPT)', International Atomic Energy Agency Bulletin, 22(3/4), pp. 73-80.

Hawkins, D. (2004) 'Explaining Costly International Institutions: Persuasion and Enforceable Human Rights Norms', International Studies Quarterly, 48(4), pp. 779-804. doi:10.1111/j.0020-8833. 2004.00325.x.

Héritier, A. and Prakash. A. (2015) 'A Resource-based View of the EU's Regional and International Leadership', Global Policy, 6 (3), pp. 247-255.

Hermann, M. G. (1980) 'Explaining Foreign Policy Behavior Using the Personal Characteristics of Political Leaders', International Studies Quarterly, 24(1), pp. 7-46. doi:10.2307/2600126.

Jervis, R. (2013) 'Do Leaders Matter and How Would We Know?', Security Studies, 22(2), pp. 153-179. doi:10.1080/09636412.2013. 786909.

Koremenos, B. (2002) 'Can Cooperation Survive Changes in Bargaining Power? The Case of Coffee', The Journal of Legal Studies, 31(s1), pp. 259-283. doi:10.1086/342009.

Koremenos, B. (2013) 'The Continent of International Law', Journal of Conflict Resolution, 57(4), pp. 653-681. doi:10.1177/00220027 12448904.

Koremenos, B. (2015) The Continent of International Law. Cambridge: Cambridge University Press (in press).

Koremenos, B. and Hong, M. H. (2013) Explaining Away the Human Rights Dummy. Working paper, University of Michigan. Available from: http://iilj.org/courses/documents/Koremenos_ExplainingAway theHumanRightsDummy.pdf [Accessed 15 June 2015].

Koremenos, B., Lipson, C. and Snidal, D. (2001) 'The Rational Design of International Institutions', International Organization, 55(4), pp. 761-799. doi:10.1162/002081801317193592.
Krasner, S. D. (1991) 'Global Communications and National Power: Life on the Pareto Frontier', World Politics, 43, pp. 336-366. doi:10.2307/2010398.

Lau, S. P. and Mui, V. (2008) 'Using Turn Taking to Mitigate Coordination and Conflict Problems in the Repeated Battle of the Sexes Game', Theory and Decision, 65, pp. 153-183. doi:10.1007/ s11238-008-9100-8.

Mattli, W. and Seddon, J. (2015) 'New Organizational Leadership: Non-state Actors in Global Economic Governance', Global Policy, 6 (3), pp. 266-276.

Saunders, E. (2011) Leaders at War: How Presidents Shape Military Interventions. Ithaca, NY: Cornell University Press.

Saz-Carranza, A. (2015) 'Agents as Broker: Leadership in Multilateral Organizations', Global Policy, 6 (3), pp. 277-289.

Schoeller, M. G. (2015) 'Explaining Political Leadership: Germany's Role in Shaping the Fiscal Compact', Global Policy, 6 (3), pp. 256265.

Shultz, G. P. (1988) 'Letter of Submittal', in Message from the President of the US Transmitting the Convention Against Torture and other Cruel, Inhuman or Degrading Treatment or Punishment. 100th US Congress. Senate. 2nd Sess., Treaty Document 100-20. Washington, DC: US Government Printing Office, pp. v-vi.

US Department of State (1959) The Antarctic Treaty [online]. Available from: http://www.state.gov/t/avc/trty/193967.htm [Accessed 9 March 2015].

UN Economic and Social Council (ECOSOC) (1964a) Commission on Human Rights, Report on the Twentieth Session (17 February-18 March 1964). New York: United Nations. UN Doc E/CN.4/874.

UN Economic and Social Council (ECOSOC) (1964b) Report of the Sixteenth Session of the Sub-Commission on Prevention of Discrimination and Protection of Minorities to the Commission on Human Rights (13-31 January 1964). New York: United Nations. UN Doc E/CN.4/873.

UN General Assembly (1965) Resolution 2106, International Convention on the Elimination of All Forms of Racial Discrimination (21 December 1965). New York: United Nations. UN Doc A/RES/ 2106.

UN General Assembly (1966) Resolution 2153 (XXI), Nonproliferation of Nuclear Weapons (17 November 1966). New York: United Nations. UN Doc A/RES/2153.

US National Security Council (1958) Report on US Policy on Antarctica Including Objectives, Major Policy Guidance, Financial Appendix, Application of a UN Trusteeship over Antarctica. Report. SECRET. Issue Date: Mar 8, 1958. Date Declassified: Sep 06, 1996. Unsanitized. Complete. 38 page(s) [online]. Available from: http://galenet.galegroup.com.proxy.lib.umich.edu/servlet/ DDRS?

$\mathrm{vrsn}=1.0 \&$ view $=$ image $\& \mathrm{~s}|\mathrm{~b}=\mathrm{KE} \& \mathrm{loc}| \mathrm{D}=$ umuser $\&$ srchtp $=$ basic $\& \mathrm{c}=2 \&$ img $=.25 \&$ page $=1 \&$ ste $=4 \&$ txb $=\mathrm{NSC}+5804$ per cent2F1\&sortType $=$ RevChron\&docNum $=$ CK2349102118 [Accessed 9 March 2015].

Wit, J. (1999) 'The Korean Peninsula Energy Development Organization: Achievements and Challenges', Nonproliferation Review, 6(2), pp. 59-69. doi:10.1080/10736709908436750.

\section{Author Information}

Barbara Koremenos is Associate Professor of Political Science at the University of Michigan. She received her PhD from the University of Chicago and won a National Science Foundation CAREER Award for her interdisciplinary research on international relations and law. Her book, The Continent of International Law, is forthcoming with Cambridge University Press. 